\title{
Normal Reference Range of Fetal Nuchal Translucency Thickness Among Pregnant Women of Igbo Extraction in Enugu, South-East Nigeria
}

\section{Charles Ugwoke Eze}

University of Nigeria - Enugu Campus

\section{Sandra Nnenna Okenwa}

University of Nigeria - Enugu Campus

Everistus obinna Abonyi ( $\boldsymbol{D}$ obinna.abonyi@unn.edu.ng )

University of Nigeria - Enugu Campus https://orcid.org/0000-0002-4967-1046

Julius Amechi Agbo

University of Nigeria - Enugu Campus

\section{Sobechukwu Warric Iwene Onwuzu}

University of Nigeria - Enugu Campus

Innocent Uchenna Nwadike

University of Nigeria - Enugu Campus

Research article

Keywords: Reference Range, Nuchal translucency, Fetal anomaly, Congenital defects, Igbo Extraction

Posted Date: July 14th, 2020

DOI: https://doi.org/10.21203/rs.3.rs-36784/v1

License: () (1) This work is licensed under a Creative Commons Attribution 4.0 International License. Read Full License 


\section{Abstract}

Background: Screening of fetus for congenital anomaly has posed a great challenge to obstetricians and other caregivers even as early identification can improve the chances of getting the best possible outcome. Early fetal anomaly screening is usually done using nuchal translucency scan and other invasive procedures such Chorionic villus sampling and amniocentesis. Increase in Nuchal translucency thickness (NTT) above a certain baseline values has been found to predict fetus with anomaly. Baseline values in use are generated from Caucasian population even though these values are known to be population specific. Hence, their use on any given population may lead to errors and introduce potential misdiagnosis. Therefore, there is need for population specific baseline values of NTT.

Objectives: The study is aimed at developing baseline values of NTT among apparently normal fetuses from pregnant women of Igbo ethnic group and to assess the relationship of NTT with maternal age and fetal gestational age (FGA).

Methods: This cross-sectional study involved 658 pregnant women of Igbo Origin between 11-14 weeks of gestation at Esut Teaching Hospital (Parklane) Enugu from August 2017 to February 2018. Pilot study was done to determine the interobserver variation between sonographers while final NTT was calculated as mean of three separate measurements. The $5^{\text {th }}, 50^{\text {th }}$ and $95^{\text {th }}$ percentiles were calculated using polynomial regression while Pearson correlation was used to determine the relationship between NTT, maternal age and FGA.

Results: The NTT measurement was shown to be reliable and reproducible. Mean \pm S/D NTT obtained was $0.92 \pm 0.23 \mathrm{~mm}$. There was a strong positive correlation between NTT measurements and FGA ( $\mathrm{r}=$ $0.823, p<0.001)$; while there was weak but positive correlation between NTT measurements and Maternal age $(r=0.055, p>0.001)$.

Conclusion: Nuchal translucency thickness measurement increases with increase in FGA while a baseline value of NTT among pregnant women of Igbo extraction has been generated.

\section{Background}

Birth defect has been a major concern for obstetricians and other health caregivers. This stems from the fact that all pregnant women are at risk of delivering fetus with physical or cognitive disability which increases with increase in maternal age ${ }^{(1)}$. Globally, approximately 9 million infants which represent about $7 \%$ of all births are born annually with serious birth defect while $94 \%$ of these defects and $95 \%$ of deaths resulting from these defects occurs in developing countries ${ }^{(2)}$. Due to the enormous burden of congenital fetal anomalies in Nigeria and other developing countries, Oloyede et al, ${ }^{(3)}$ opined that adequate attention is needed to stem the tide.

Early detection of fetuses with defect is of utmost important as decision to terminate the pregnancy will be safer at first trimester when compared to second and third trimester ${ }^{(3)}$. Early screening of fetuses for 
birth defect is done through Amniocentesis, Chorionic villi sampling or Nuchal translucency scan. Amniocentesis and Chorionic villi sampling which are confirmatory tests for fetus at risk of abnormalities like Down syndrome, trisomy 21,18 and 13 , are highly invasive with the attendant risk of miscarriage ${ }^{(4)}$.. Nuchal translucency thickness assessment offers a non-invasive means of detecting fetuses at risk of birth defect and is also an important tool in the prediction of fetal aneuploidy ${ }^{(5)}$. Nuchal translucency refers to the layer of subcutaneous fluid behind the fetal neck and lower cranium ${ }^{(6)}$. It can be measured using imaging modalities like magnetic resonance imaging (MRI) and ultrasonography. MRI gives better resolution of image than ultrasound, but due to the involuntary movement of the fetus with its attendant motion artifact, expensive nature and unavailability, MRI is not the preferred imaging modality ${ }^{(7)}$. Ultrasonography remains the best imaging modality of choice for nuchal translucency measurement as a screening tool because of its non- invasiveness, availability, relatively low cost, real time capability and operator comfort ${ }^{(8)}$.

Ultrasound measurement of nuchal translucency is performed between 11-14 weeks of gestation or when the fetal length measures between $45-84 \mathrm{~mm}^{(3,9)}$. Due to the strong relationship between increase in thickness of nuchal translucency with chromosomal anomalies and other adverse pregnancy outcomes, NTT is used to screen women at risk of fetal birth defect ${ }^{(10)}$. Nuchal translucency in combination with maternal age and serum markers provide a a reliable marker for predicting the risk of abnormality, although, NTT is $70 \%$ accurate in predicting Down syndrome ${ }^{(11)}$. Nuchal translucency diameter of $3.5 \mathrm{~mm}$ or more has been considered significant and required further investigations to rule out the risk of fetal birth defect ${ }^{(12)}$. It is pertinent to know that nuchal translucency was introduced into clinical practice with most of the derived data obtained from researches conducted in Europe which uses mainly Caucasian population. These derived data are then applied to all women irrespective of their ethnicity ${ }^{(9)}$. Studies in Iran, Japan, Korean, Austrian and Brazilian population ${ }^{(13-17)}$ reported varying median nuchal translucency in the ranges of $1.0-1.4 \mathrm{~mm}, 1.2-1.9 \mathrm{~mm}, 1.22-2.10 \mathrm{~mm}, 0.5-2.0 \mathrm{~mm}$ and 1.19-1.73 $\mathrm{mm}$ respectively. These ethnic variations tend to further confirm the finding of Sharifzadeh et al ${ }^{(13)}$ that NTT varies with ethnicity. The implication of this is that using Caucasian values on our locality may be erroneous, thus, the need to have a population specific chart.

In Nigeria, Oloyede et al (3) carried out a study on nuchal translucency in Lagos, South-South Nigeria and found that screening using NTT is feasible in Nigeria. In spite of this, there is paucity of data on sonographic assessment of NTT in South-Eastern Nigeria which is dominated by Igbo ethnic group. This study is therefore, aimed at providing a baseline nuchal translucency measurement of apparently normal fetuses among pregnant women of Igbo ethnic origin and to compare the result of this study with those of other studies.

\section{Methods}

This was a cross sectional study carried out on pregnant women from selected healthcare centers in Southeastern Nigeria between August 2017 and February 2018. A purposive sampling method was used 
to recruit 658 pregnant women who met the inclusion criteria and consented to the exam. Inclusion criteria include all apparently health singleton pregnant women of Igbo extraction within 11-14 weeks of gestation with known LMP which corresponds to dating with ultrasound CRL. Pregnancies with Poly- or Oligo-hydramnios, placenta abruption, obvious fetal anomaly, subjects with unsure LMP or whose LMP differs from CRL measurement by one week and those that didn't consent to the study were excluded. Ethical approval was sort and obtained from the ethics committee of Enugu State University Teaching Hospital (Parklane) Enugu.

\section{Equipment}

Sonographic measurement of fetal NT was performed using real time digital ultrasound scanner model (DP-50) manufactured by Shenzhen Mindray Biomedical Electronics Co. Ltd. China, 2017) with $3.5 \mathrm{MHz}$ frequency convex transducer.

\section{SCANNING TECHNIQUE}

Prior to actual study, a pilot study was carried out on 30 patients to assess the reliability and reproducibility of nuchal translucency measurement within and between sonographers with more than 15 years of experience. 'Fetuses were examined in longitudinal plane with the neck in neutral position while the palate, diencephalon and the nasal bone are in profile ${ }^{(18)}$. To differentiate between the amnion and overlying fetal skin, fetal movement was patiently waited for or elicited by a gently perturbing the maternal abdomen ${ }^{(9)}$.. Measurement of NTT was taken using electronic caliper from inner border to inner border and the mean of three different measurements were used ${ }^{(19)}$.

\section{Statistical Analysis}

Statistical analysis was performed using Statistical Software Package for Social Science (SPSS) window version 20.0 (IBM Corp. Armonk, NY: USA). Descriptive statistics was used to determine the mean and standard deviation of NTT. Intraclass correlation coefficient was used to determine the reproducibility and reliability of NTT measurement within and between two sonographers. The 5th, 50th and 95th percentiles according to FGA and CRL respectively were calculated using polynomial regression. Pearson product moment correlation coefficient and linear regression were used to assess the strength and relationship between NTT and maternal age, fetal age and CRL. Independent sample t-test was used to determine whether there is significant difference between our values and that obtained from Caucasians. P-value of $<0.001$ was considered statistically significant.

\section{Results}

A total number of 934 pregnant women presented for scan within the period of study. Six hundred and fifty-eight (658) met the inclusion criteria and were selected while 276 subjects were excluded for the following reasons- 203 patients were excluded for unsure LMP, 70 didn't consent to the study while 3 had 
obvious fetal anomaly. The age range of patients who met the inclusion criteria was shown in Table 1 with age range of 26-30 years having the highest frequency while 18 years and below has the lowest frequency. Mean CRL and gestational age are $68.61 \pm 13.22 \mathrm{~mm}$ and $12.76 \pm 1.08$ weeks respectively.

Table 1: Mean and ranges of the variable in the study

\begin{tabular}{|llcc|}
\hline Variables & Mean \pm SD & Median & Range \\
\hline Maternal Age (yrs.) & $29.77 \pm 5.67$ & 29.00 & $18.00-49.00$ \\
\hline Crown-rump-length (mm) & $68.61 \pm 13.22$ & 70.10 & $45.00-84.00$ \\
\hline Gestational Age (wks.) & $12.76 \pm 1.08$ & 13.00 & $11.00-14.00$ \\
\hline Nuchal Translucency thickness (mm) & $0.92 \pm 0.23$ & 0.90 & $0.40-2.00$ \\
\hline
\end{tabular}

\section{Reliability and Agreement of nuchal translucency measurement.}

Measurement of nuchal translucency thickness shows excellent reproducibility and reliability with intraclass correlation coefficient of 0.994 within sonographers and 0.989 between sonographer (Tables 2 and 3$)$. Also, Bland Altman plot shows no trend below and above the mean difference line $( \pm 1.65)$ which suggest good agreement between measurements. Also, to test for proportional bias, a linear regression was run on the mean difference and a p-value of 0.858 was obtained which also confirm lack of bias among the two sonographers.

Table 2

Intraclass Correlation Coefficient for single sonographer

\begin{tabular}{|c|c|c|c|c|c|c|c|}
\hline & \multirow{2}{*}{$\begin{array}{l}\text { Intraclass } \\
\text { Correlation }^{b}\end{array}$} & \multicolumn{2}{|c|}{ 95\% Confidence Interval } & \multicolumn{4}{|c|}{ F Test with True Value 0} \\
\hline & & $\begin{array}{l}\text { Lower } \\
\text { Bound }\end{array}$ & $\begin{array}{l}\text { Upper } \\
\text { Bound }\end{array}$ & Value & $\mathrm{df} 1$ & $\mathrm{df} 2$ & Sig \\
\hline $\begin{array}{l}\text { Single } \\
\text { Measures }\end{array}$ & $.988^{\mathrm{a}}$ & .970 & .995 & 169.048 & 18 & 18 & .000 \\
\hline $\begin{array}{l}\text { Average } \\
\text { Measures }\end{array}$ & $.994^{\mathrm{C}}$ & .985 & .998 & 169.048 & 18 & 18 & .000 \\
\hline
\end{tabular}


Table 3

Interclass Correlation Coefficient between two Sonographers

\section{Interclass Correlation Coefficient for two sonographers}

\begin{tabular}{|c|c|c|c|c|c|c|c|}
\hline & \multirow{2}{*}{$\begin{array}{l}\text { Interclass } \\
\text { Correlation }^{\text {b }}\end{array}$} & \multicolumn{2}{|c|}{ 95\% Confidence Interval } & \multicolumn{4}{|c|}{ F Test with True Value 0} \\
\hline & & $\begin{array}{l}\text { Lower } \\
\text { Bound }\end{array}$ & $\begin{array}{l}\text { Upper } \\
\text { Bound }\end{array}$ & Value & df1 & $\mathrm{df} 2$ & Sig \\
\hline $\begin{array}{l}\text { Single } \\
\text { Measures }\end{array}$ & $.978^{a}$ & .945 & .992 & 91.781 & 18 & 18 & .000 \\
\hline $\begin{array}{l}\text { Average } \\
\text { Measures }\end{array}$ & $.989^{c}$ & .972 & .996 & 91.781 & 18 & 18 & .000 \\
\hline
\end{tabular}

\section{Relationship between NTT, FGA and CRL.}

The relationship between NTT and FGA in the studied population was linear as depicted in the scatter diagram (Fig. 2). A linear regression model fits the data with the relationship being defined by the regression model equation which is as follows:

Nuchal Translucency Thickness $($ NTT $)=0.164$ x FGA - 1.174. Eq. 1

Also, the relationship between Nuchal translucency thickness and crown-rump-length was linear as depicted in scatter diagram (Fig. 3). Also, a linear regression model fits the data and the following model equation was generated:

$\mathrm{NTT}=0.015 \times \mathrm{CRL}-0.129$. Eq. 2

From the percentile chart (Tables 4 and 5), nuchal translucency thickness was found to increase as fetal gestational age increases. The mean NTT from this study was $0.92 \pm 0.23 \mathrm{~mm}$ while NTT value increases from $0.60 \pm 0.07 \mathrm{~mm}$ at 11 weeks of gestation to a value of $1.17 \pm 0.14 \mathrm{~mm}$ at 14 weeks of gestation. In the same way, there was also a linear increase in nuchal translucency thickness with increase in crownrump-length (CRL) with median NTT increasing from $0.60 \mathrm{~mm}$ at CRL of $45 \mathrm{~mm}$ to $1.17 \mathrm{~mm}$ at CRL of $85 \mathrm{~mm}$. 
Table 4. Percentile chart of Nuchal

Translucency (NT) and Gestational Age (GA)

\begin{tabular}{|lllll|}
\hline GA (wks.) $\uparrow$ & 11 & 12 & 13 & 14 \\
$/ \mathrm{NT}(\mathrm{mm}) \downarrow$ & & & & \\
\hline $5^{\text {th }}$ & 0.50 & 0.70 & 0.80 & 1.00 \\
\hline $25^{\text {th }}$ & 0.60 & 0.70 & 0.90 & 1.03 \\
\hline $50^{\text {th }}$ & 0.60 & 0.80 & 0.90 & 1.17 \\
\hline $75^{\text {th }}$ & 0.69 & 0.80 & 0.93 & 1.27 \\
\hline $95^{\text {th }}$ & 0.70 & 0.90 & 1.00 & 1.43 \\
\hline
\end{tabular}

Table 5

Percentile chart of NT and CRL

\begin{tabular}{|llllllllll|}
\hline $\begin{array}{l}\text { CRL(mm) } \\
\text { NT } \\
(\mathrm{mm}) \downarrow\end{array}$ & $\mathbf{4 5}$ & $\mathbf{5 0}$ & $\mathbf{5 5}$ & $\mathbf{6 0}$ & $\mathbf{6 5}$ & $\mathbf{7 0}$ & $\mathbf{7 5}$ & $\mathbf{8 0}$ & $\mathbf{8 5}$ \\
\hline 5th & 0.40 & 0.50 & 0.52 & 0.68 & 0.70 & 0.72 & 0.82 & 0.83 & 1.00 \\
\hline 25th & 0.55 & 0.59 & 0.60 & 0.70 & 0.73 & 0.80 & 0.90 & 0.90 & 1.06 \\
\hline 50th & 0.60 & 0.60 & 0.70 & 0.80 & 0.80 & 0.90 & 0.90 & 0.93 & 1.17 \\
\hline 75th & 0.62 & 0.70 & 0.79 & 0.80 & 0.80 & 0.90 & 0.97 & 1.00 & 1.28 \\
\hline 95th & 0.72 & 0.70 & 0.85 & 0.83 & 0.90 & 0.97 & 1.00 & 1.27 & 1.43 \\
\hline
\end{tabular}

\section{Relationship between maternal age and NTT}

Pearson product moment correlation was used to determine the relationship between the maternal age and nuchal translucency and a value of $r=0.055$ was obtained which shows a very weak but positive relationship existing between them. This is supported by a scatter plot of nuchal translucency with maternal age which shows no pattern. (Fig. 4) 


\section{Discussion}

Congenital anomalies have been found to be the major cause of neonatal mortality and morbidity in developing countries of which Nigeria is among ${ }^{(20)}$. According to Ndibazza et al, ${ }^{(21)}$, an estimated 7.9 million children are delivered with major congenital anomalies yearly while the prevalence increasing from $3 \%$ in 2008 to $4.4 \%$ in $2013^{(22)}$. This alarming rate of fetal anomaly calls for concerted effort in curbing such a menace. Early screening of fetus for anomaly becomes imperative as early identification of such anomaly could alter the obstetric management of fetus for a better outcome. Nuchal translucency screening has proved effective in the identification of fetus that are at risk of congenital anomalies.

In our study, the mean, median and ranges of maternal age, CRL, FGA and NTT are presented in Table 1 with mean maternal age being $29.77 \pm 5.67$ years while mean CRL, FGA and NTT are $68.61 \pm 13.22 \mathrm{~mm}$, $12.76 \pm 1.08 \mathrm{wks}$. and $0.92 \pm 0.23 \mathrm{~mm}$ respectively.

Also, from our study, booking at 14 weeks of gestation has the highest frequency while that of 11 weeks of gestation has the lowest frequency. This goes to support the finding of Atombosoba et al, ${ }^{(23)}$ who found that most women book late for antenatal which implies that at the time of booking, most fetal anomalies must have gone beyond redemption, thus increase number of children with birth defect in developing countries ${ }^{(23)}$. Reference range values of median NTT obtained from our study ranges from $0.60 \pm 0.07 \mathrm{~mm}$ at 11 weeks of gestation to $1.17 \pm 0.14 \mathrm{~mm}$ at 14 weeks of gestation while the 95th percentile value range was $0.7 \mathrm{~mm}$ at 11 weeks of GA and $1.43 \mathrm{~mm}$ at 14 weeks of GA. Furthermore, 95th percentile value for $C R L$ ranges from $0.72 \mathrm{~mm}$ at $C R L$ of $45 \mathrm{~mm}$ to $1.43 \mathrm{~mm}$ at $C R L$ of $85 \mathrm{~mm}$. This is

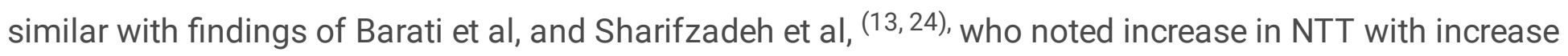
in both FGA and CRL.

Ethnicity has been a factor in the variations of NTT across different sampled populations. This was supported by Chen et al ${ }^{(25)}$ who stated that differences noted in the NTT from different studied population should be attributed to difference in race. Findings from our study shows that at 13 weeks GA, the 95th reference values ranges from 0.70 to $1.43 \mathrm{~mm}$ while the 95 th reference values from study by Sharifzadeh et al, ${ }^{(13)}$ ranges from 1.0 to $2.19 \mathrm{~mm}$. When these studies were subjected to statistical analysis, it showed statistically significant difference between the two studied groups with p-value 0.046 . This could be attributed to the difference in the morphology of the populations studied. This is also in line with the findings of Spencer et al, (26) who noted that NTT in Afro-Caribbean women were $0.064 \mathrm{~mm}$ lower on average than that in Caucasian women while it is $0.045 \mathrm{~mm}$ lower than that in South Asian women.

Results from this study shows that there is positive but very weak correlation between maternal age and nuchal translucency. The implication of this is that maternal age has no influence of the thickness of nuchal translucency. This, also, conforms to the finding of Oloyede et al, (3) and Barati et al, ${ }^{(23)}$ who found no significant relationship between maternal age and nuchal translucency thickness. 


\section{Conclusion}

Fetal nuchal translucency thickness has been found to increase with both fetal gestational age and crown-rump-length. There is no significant relationship between fetal nuchal translucency thickness with maternal age while statistically significant difference was noted between our study and that of Sharifzadeh et al ${ }^{(13)}$ done-on Caucasians. Therefore, a population specific reference range value of nuchal translucency thickness among pregnant women of Igbo origin was generated.

\section{Recommendations}

We recommend that adequate sensitisation should be made so that pregnant mothers will know the benefit of early registration for antenatal clinic.

\section{Abbreviations}

NTT: Nuchal translucency thickness

FGA: Fetal gestational age,

LMP: Last menstrual period,

CRL: Crown rump length,

MRI: Magnetic resonance imaging

\section{Declarations}

\section{Ethical Approval and Informed Consent:}

Ethical Approval was obtained from a tertiary institution with reference number ESUTHP/CMAC/RA/034/216 while informed consent was obtained from patient before scanning her as no patient is below 16 years of age.

\section{Consent for publication:}

Not Applicable

\section{Availability of data and materials:}

Due to patient privacy protection, the data and corresponding materials used in this study are with the corresponding author and can only be made available upon request. 


\section{Competing interest:}

The authors declare that they have no competing interests.

\section{Funding:}

None.

\section{Authors' contributions:}

ECU, OSN and AEO designed the study, OSN performed the ultrasound scanning, AEO, AJA and NIU drafted the manuscript, and OSWI analyzed the data. All the authors read the manuscript and therefore approved the final manuscript for submission

\section{Acknowledgements:}

Not Applicable.

\section{References}

1. Joseph KS, Allen AC, Dodds L, Turner LA, Scott H, Liston R. The perinatal effects of delayed childbearing. Obstetrics and Gynaecology. 2005; 105(6):1410-8.

2. World Bank Country Classification. 2005. [Accessed October 16, 2017]. Available from: worldbank.Org/data/countryclass/countryclass.html.

3. Oloyede, O. A., Abbey, M., Oloyede, A. A., Nwachukwu, O. Fetal nuchal translucency scan in Nigeria. The Pan African Medical Journal. 2014; 18, 62. http://doi.org/10.11604/pamj.2014.18.62.3291.

4. Mujezinovic F, Alfirevic Z. Procedure-related complications of amniocentesis and chorionic villous sampling: A systematic review. Obstet Gynecol. 2007; 110:687-94.

5. Zalel, Y., Zemet, R., and Kivilevitch, Z. The added value of detailed early anomaly scan in fetuses with increased nuchal translucency. Prenatal Diagnosis. 2017; 37: 235-243. doi: 1002/pd.4997.

6. Dey, M., Sharma, S., \& Aggarwal, S. Prenatal Screening Methods for Aneuploidies. North American Journal of Medical Sciences. 2013; 5(3), 182-190. http://doi.org/10.4103/1947-2714.109180

7. Reddy, U. M., Filly, R. A., \& Copel, J. A. Prenatal Imaging: Ultrasonography and Magnetic Resonance Imaging. Obstetrics and Gynaecology. 2008; 112(1), 145-157. http://doi.org/10.1097/01.AOG.0000318871.95090.d9.

8. Pugash Denise, Peter C. Brugger, Dieter Bettelheim, Daniela Prayer. Prenatal ultrasound and fetal MRI: The comparative value of each modality in prenatal diagnosis. European journal of Radiology. 2008; 68(2), 214-226. 
9. Nicolaides KH1, Heath V, Cicero S. Increased fetal nuchal translucency at 11-14 weeks. Prenatal Diagnosis. 2002; 22(4), 308-315

10. Pérez SP, Seguer JJ, Azuara LS, Pueyo JC, Juanos JL, et al. Contribution of Chromosomal Microarray Analysis in foetuses with Increased Nuchal Translucency: A Prospective Observational Study. Gynaecology and Obstetrics (Sunnyvale). 2018; 8: 479. doi: 10.4172/2161-0932.1000479

11. Smith, M., \& Visootsak, J. Noninvasive screening tools for Down syndrome: a review. International Journal of Women's Health. 2013; 5, 125-131. http://doi.org/10.2147/IJWH.S31183.

12. Salman G. S. The Associations of Nuchal Translucency and Fetal Abnormalities; Significance and Implications. Journal of Clinical and Diagnostic Research: JCDR. 2013; 7(5), 936-941. http://doi.org/10.7860/JCDR/2013/5888.2989.

13. Sharifzadeh, M., Adibi, A., Kazemi, K., \& Hovsepian, S. Normal reference range of fetal nuchal translucency thickness in pregnant women in the first trimester, one center study. Journal of Research in Medical Sciences: The Official Journal of Isfahan University of Medical Sciences. 2015, 20(10), 969-973.

14. Hasegawa J, Nakamura M, Hamada S, Matsuoka R, Ichizuka K, Sekizawa A. Distribution of nuchal translucency thickness in Japanese fetuses. The Journal of Obstetrics and Gynaecology Research. 2013; 39:766-9.

15. Chung JH, Yang JH, Song MJ, Cho JY, Lee YH, Park SY. The distribution of fetal nuchal translucency thickness in normal Korean fetuses. Journal of Korean Medical Science. 2004; 19:32-6.13.

16. Schuchter Katharina, Nicholas Wald, Allan K. Hackshaw, Erich Hafner, Eva Liebhart. The distribution of nuchal translucency at 10-13 weeks of pregnancy. Prenatal diagnosis. 1998; 18(3). 281286xDieter Bettelheim.

17. Araujo Júnior E, Pires CR, Martins WP, Nardozza LM, Filho SM. Reference values of nuchal translucency thickness in a Brazilian population sample: Experience from a single centre. Journal of Perinatal Medicine. 2014; 42:255-9.

18. The Fetal Medicine foundation. Accessed July 2017. https://fetalmedicine.org/nuchal-translucencyscan

19. Suchet I. B. Normal Values for the Nuchal Translucency And The Technique For Measurement. The ultrasound of life. 2013. fetalultrasound.com.

20. Ajao A. E, Adeoye I. A. Prevalence, Risk Factors and Outcome of Congenital Anomalies Among Neonatal Admissions in Ogbomoso, Nigeria. BMC Pediatrics. 2019; 19(1): 88. doi: 10.1186/s12887019-1471-1.

21. Ndibazza J, Lule S, Nampijja M, et al. A description of congenital anomalies among infants in Entebbe, Uganda. Birth Defects Res A Clin Mol Teratol. 2011;91(9):857- doi:10.1002/bdra.20838.

22. Liu L, Oza S, Hogan D, Perin J, Rudan I, Lawn JE, et al. Global, regional, and national causes of child mortality in $2000-13$, with projections to inform post-2015 priorities: an updated systematic analysis. 2015; 385:430-440. doi: 10.1016/S0140-6736(14)61698-6. 
23. Atombosoba AE, Obaabo W, Judit Al. Patients Attitude towards Antenatal care and Factors Determining it's Uptake in a Rural Communities in the Niger Delta, Nigeria. J Pharm Biomed Sci. 2015;05(04):344-350. Available at jpbms.info

24. Barati M, Zargar M, Masihi S, Taherpour S. Evaluation of nuchal translucency measurement in first trimester pregnancy. Int J Fertil Steril. 2011;5(1):35-

25. Chen Min, Yung Hang Lam, Mary Hoi Yin Tang, Chin Peng Lee, Sai Yuen Sin Rebecca Tang, Hong Soo Wong, Sai Fun Wong. The effect of ethnic origin on nuchal translucency at 10-14 weeks of gestation. Prenaatal diagnosis. 2002; 22(7). 576-578. https://doi.org/10.1002/pd.363

26. Spencer K, Heath V, El-Sheikhah A Y. T. Ong K. H. Nicolaides. Ethnicity and the need for correction of biochemical and ultrasound markers of chromosomal anomalies in the first trimester: a study of Oriental, Asian and Afro-Caribbean populations. Prenatal diagnosis. 2005; 25(5). 365-369 https://doi.org/10.1002/pd.1153

\section{Figures}

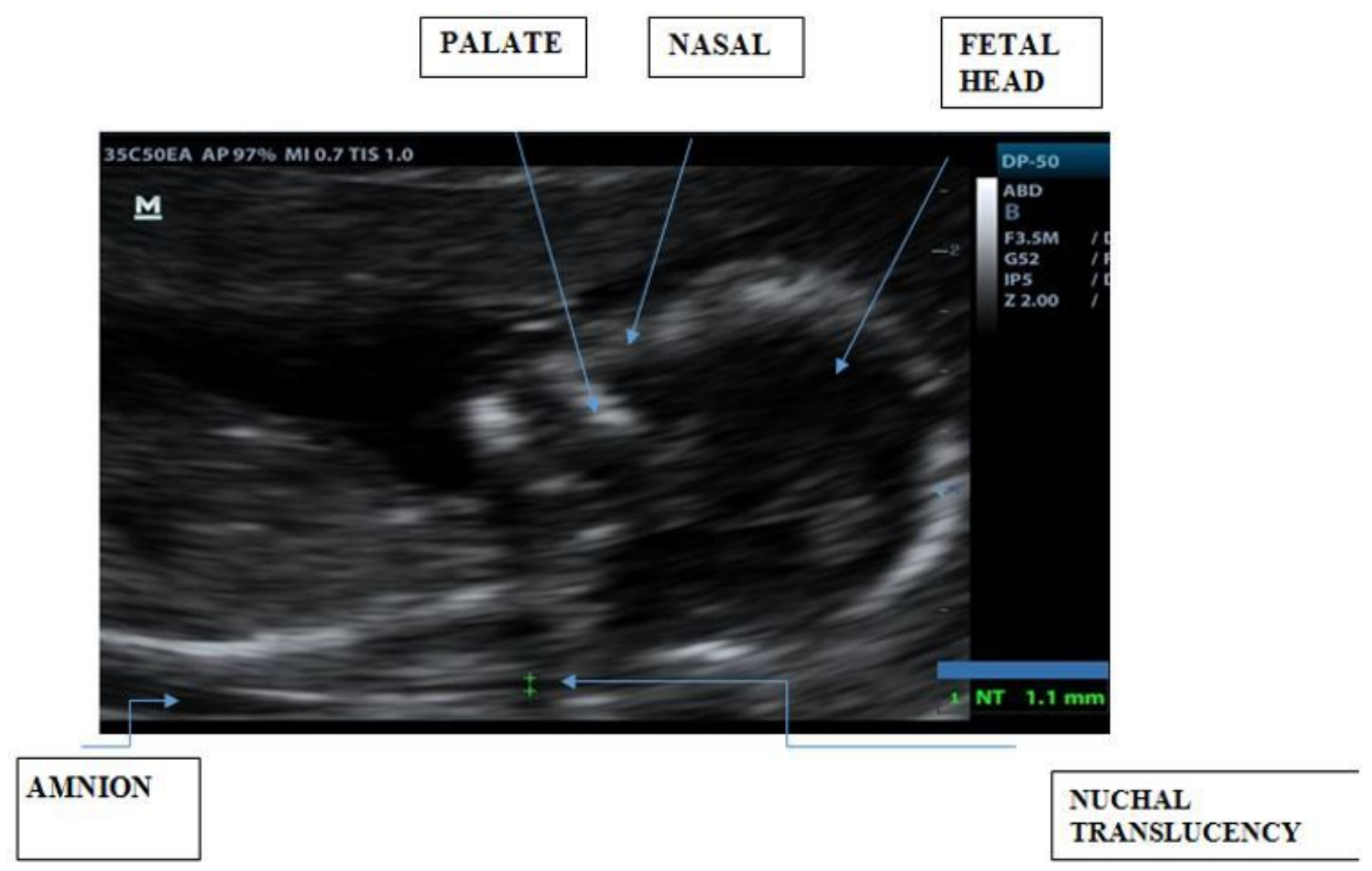

\section{Figure 1}

Sonogram of Fetal Nuchal Translucency Thickness Measurement. 


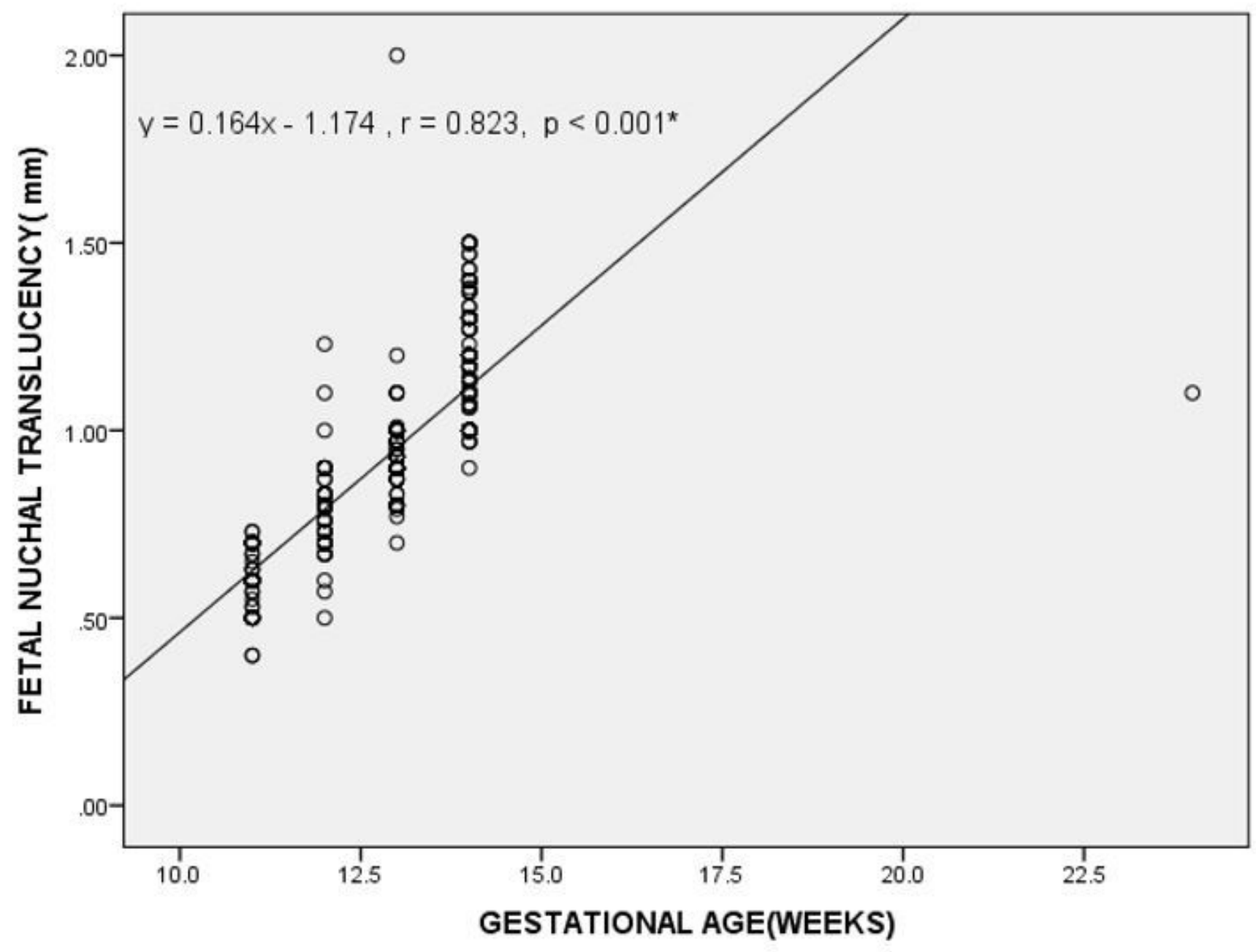

Figure 2

Scatterplot of Nuchal translucency with Fetal Gestational Age 


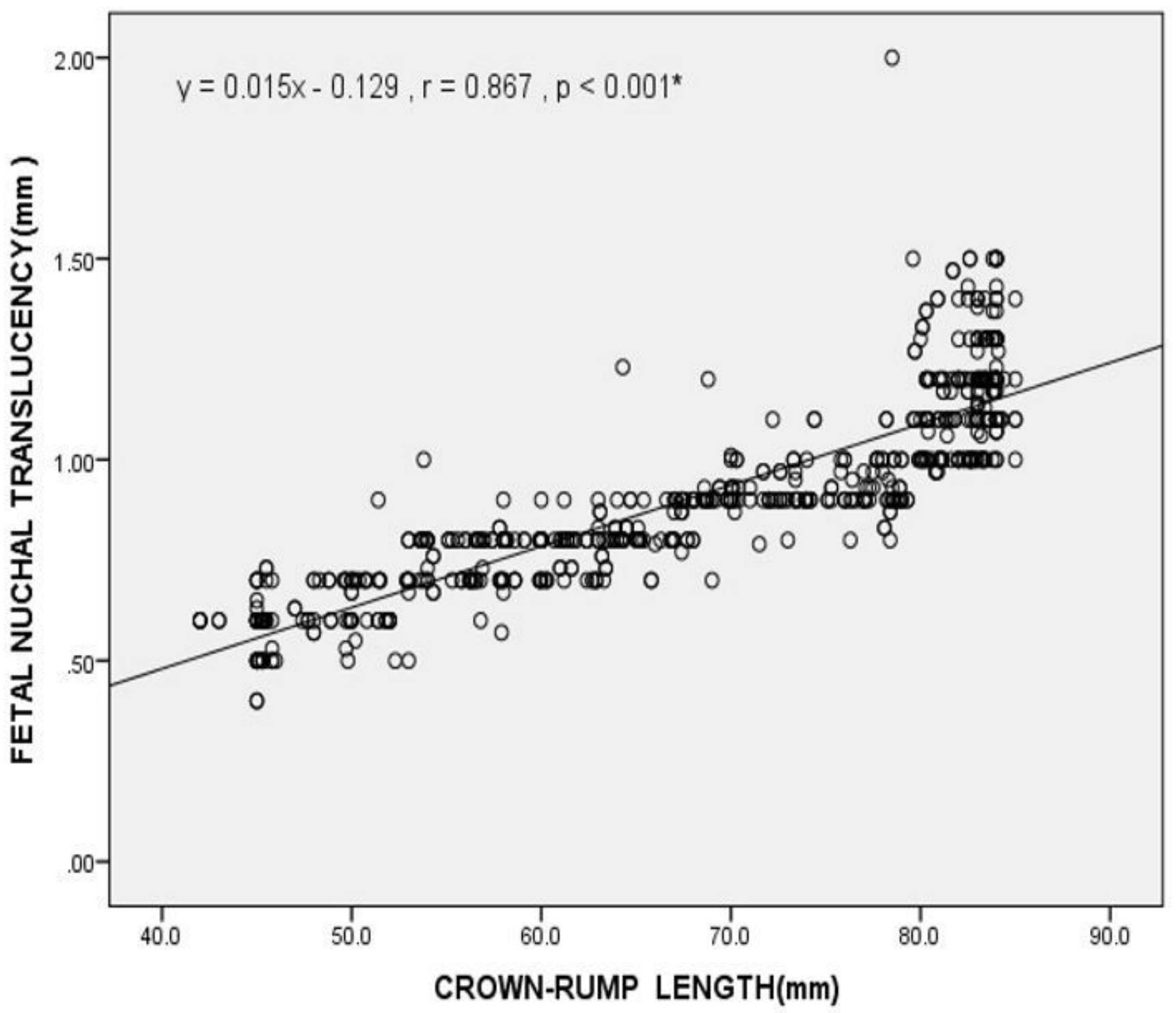

Figure 3

Scatterplot of Nuchal Translucency with Crown-Rump-Length. 


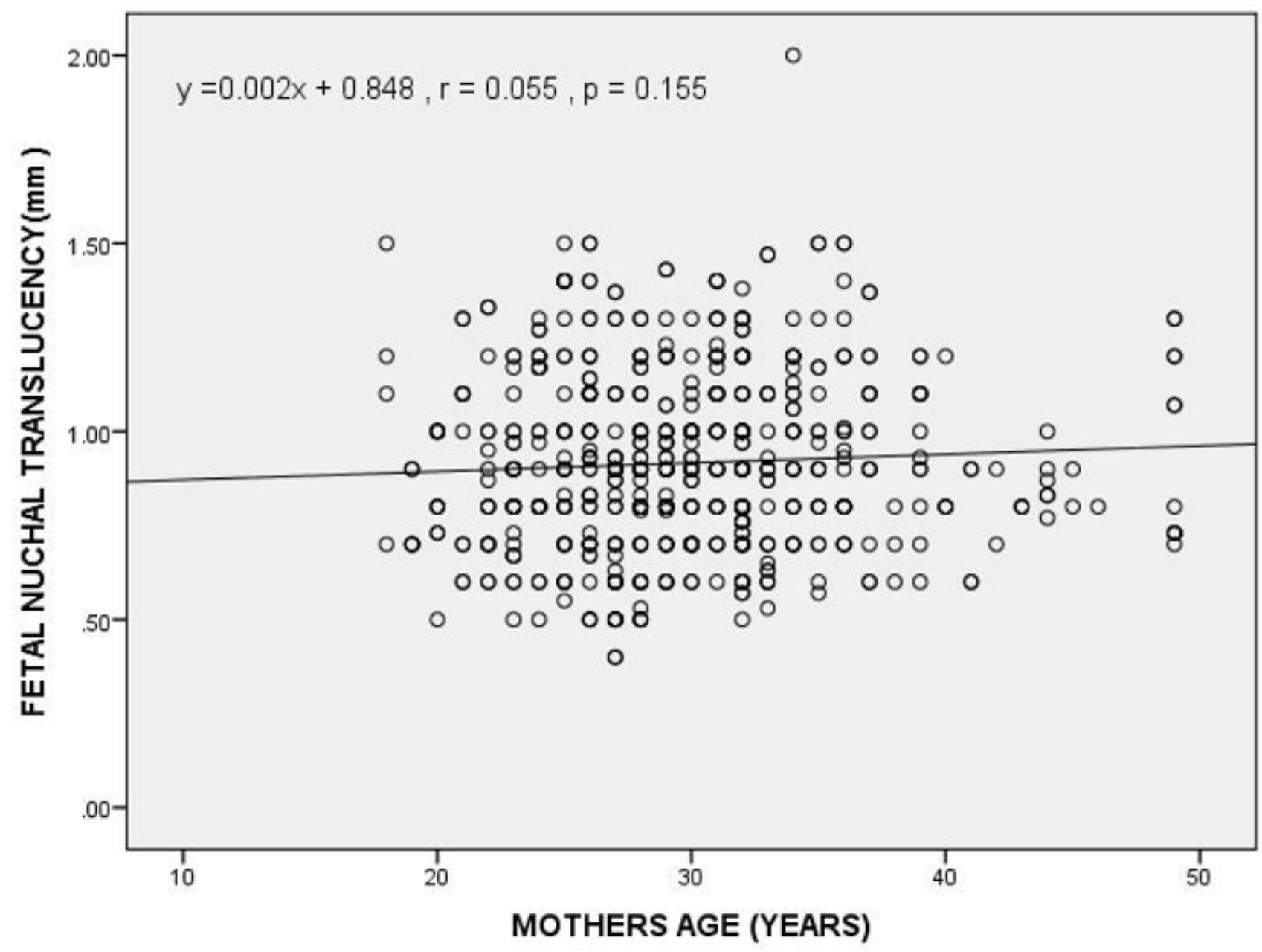

Figure 4

Scatterplot of Nuchal Translucency with Maternal Age 